,

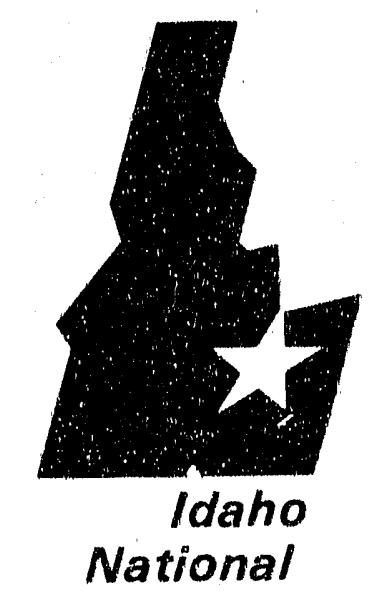

Engineering

Laboratoiy

\author{
Managed \\ by the U.S. \\ Department \\ of Energy
}

EGG-GEO-10330

June 1992
INDEPENDENT VEFIFICATION AND

VALIDATION TESTING OF THE FLASH COMPUTER CODE, VERSION 3.0
Pete Martian

Jacob N. Chung

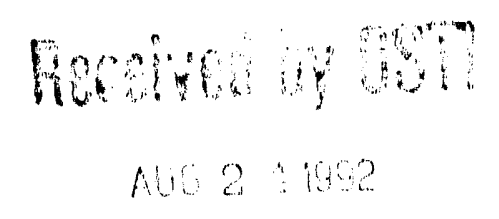

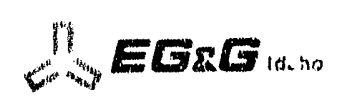

Work performoot under DOE Contract No. DE-ACO7.761DO1570 


\section{OISCLAIMER}

This book was orebared as an account of work soonsored by an agency of the United States Covernment. Nenther the Uniced Siates Government nor any agency thereot. nor any of iner omployees, makes any warranty, express or imslied, or assumes any egal liability or responsibility for the accuracy, completeness, or usefulness of any information, apparatus, product of process disctosed, or represents thai its use would not intmige privately ownerd rights. Reterences nerein ro dny soecific comrnercial oroduct. piocess, of service by rrade name, trademark, manulacturer. or otherwisa. does not nea'ssanty consetute or imply its andorsernent, res:ommendation. so favering by the United States Government or any agency thereot. The views and opinions of authors expressed herern do not neciessarily state or reflect these of the United States Governmrnt or amy agmery tmeretot. 


\title{
INDEPENDENT VERIFICATION AND VALIDATION TESTING OF THE FLASH COMPUTER CODE, VERSION 3.0
}

\author{
Pete Martian \\ Jacob N. Chung \\ June 1992 \\ Department of Mechanical and Materials Engineering \\ Washington State University \\ Pullman, Washington 99164
}

Prepared for EG\&G Idaho, Inc.

Under Subcontract No, C85-110796-010 and for the

U. S. Department of Energy

Office of Environmental Restoration and Wasto Management

Under DOE Idaho Field Office Contract No. DE.AC07-761DO1570

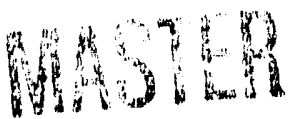




\section{$\underline{A B S T R A C T}$}

Independent testing of the FLASH computer code, Version 3.0, was conducted to determine if the code is ready for use in hydrological and environmental studies at various Department of Energy sites. This report describes the technical basis, approach, and results of this testing. Verification tests, (i.e., tests which compare analytical solutions to the computer generated solutions) and validation tests, (i.e., tests which compare field data to the computer generated solutions) were used to determine the operational status of the FLASH computer code. These tests were specifically designed to test: (1) correctness of the FORTRAN coding, (2) coniputational accuracy, and (3) suitability to simulating actual hydrologic conditions.

This testing was performed using a structured evaluation protocol which consisted of: (1) blind testing, (2) independent applications, and (3) graduated wifficulty of test cases. Both quantitative and qualitative testing was perfurmed through evaluating relative root mean square (RRMS) values and graphical comparisons of the numerical, analytical, and experimental data.

Four verification test were used to check the computational accuracy and correctness of the FORTRAN coding, and three validation tests were used to check the suitability to simulating actual conditions. These test cases ranged in complexity from simple 1-D saturated flow to 2-D variably saturated problerns.

The verification tests showed excellent quantitative agreement between the FL.ASH results and analytical solutions. The validation tests showed good qualitative agreement with the experimental data. Based on the results of this testing, it was concluded that the FLASH code is a versatile and powerful two-dimensional analysis tool for fluid flow. In conclusion, all aspects of th code that were tested, except for the unit gradient bottom boundary condition, were found to be fully operational and ready for use in hydrological and environmental studies. 


\section{Table of Contents}

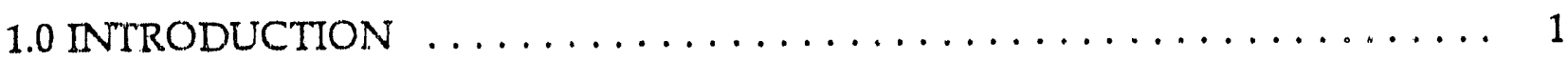

1.1 Background . . . . . . . . . . . . . . . . . . . . . 1

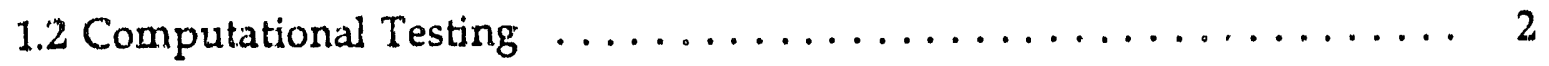

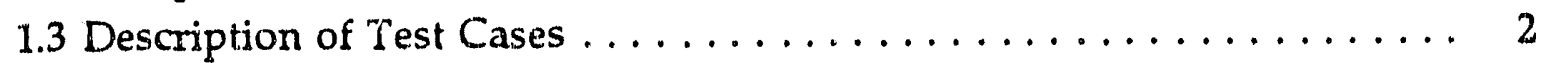

2.0 TEST APPROACH AND REQUTREMENTS $\ldots \ldots \ldots \ldots \ldots \ldots \ldots \ldots \ldots$

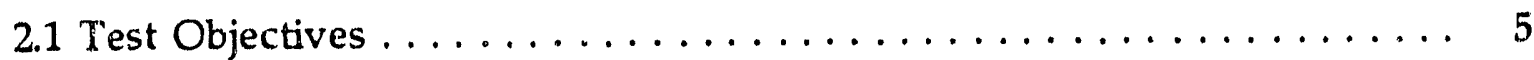

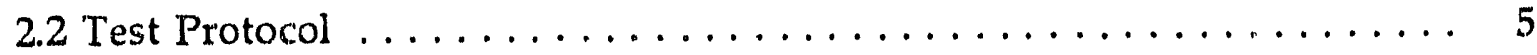

2.3 Performance Indicators $\ldots \ldots \ldots \ldots \ldots \ldots \ldots \ldots \ldots \ldots \ldots \ldots \ldots \ldots \ldots$

3.0 VERIFICATION TESTS $\ldots \ldots \ldots \ldots \ldots \ldots \ldots \ldots \ldots \ldots \ldots \ldots \ldots$

3.1 Philip's Solution for A Vertical Column . . . . . . . . . . . . . . 7

3.2 Aquifer Response to a Change in Reservoir Level . . . . . . . . . . . . 10

3.3 Regional Flow in a Groundwater Rectangle . . . . . . . . . . . . . . . 13

3.4 Boussinesq Similarity Solution for an Unconfined

Aquifer ............................. 16

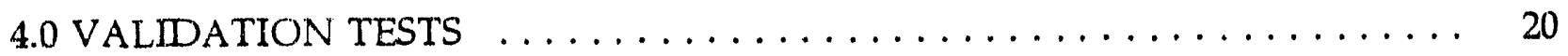

4.1 Los Alamos Caisson Experiment for Steady-State

Flow ............................ 20

4.2 Los Alamos Caisson Experiment for a Transient Water

Pulse ............................ 24

4.3 Las Cruces Trench Experiment $\ldots \ldots \ldots \ldots \ldots \ldots \ldots \ldots \ldots$

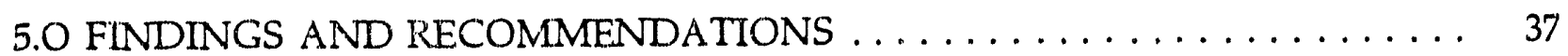

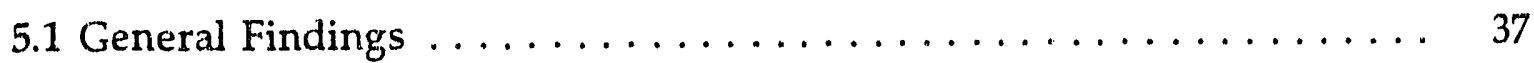

5.2 Recommended Refinements . . . . . . . . . . . . . . 38

5.3 Recommendations for Additional Testing $\ldots \ldots \ldots \ldots \ldots$

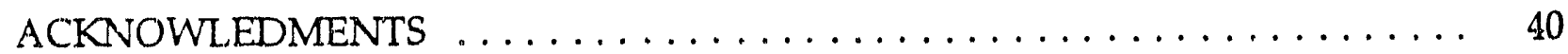

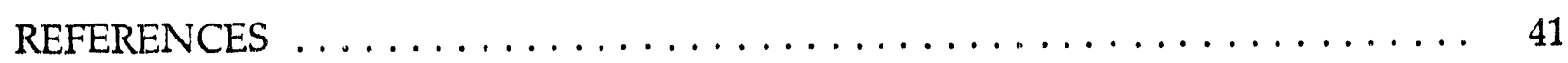




\section{Table of Contents (Continued)}

APPENDIX A - SUMMARY OF RRMS RESULTS

\section{List of Figures}

1 Comparison of Pressure Heads for Test VT $-1 \ldots \ldots \ldots \ldots \ldots \ldots \ldots$

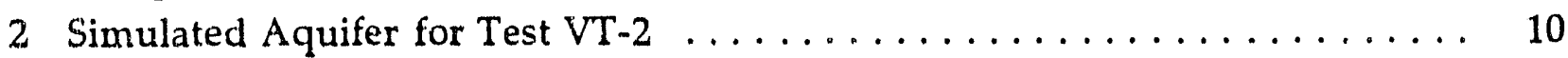

3 Comparison of Pressure Heads for Test VT $-2 \ldots \ldots \ldots \ldots \ldots \ldots \ldots \ldots, 12$

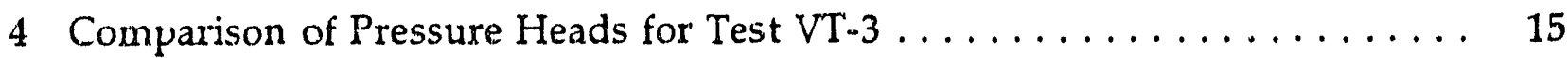

5 Comparison of Relative Pressures for Test VT $-4 \ldots \ldots \ldots \ldots \ldots \ldots \ldots \ldots$

6 Comparison of Head Variation for Test VT $-4 \ldots \ldots \ldots \ldots \ldots \ldots \ldots \ldots$

7 Los Alamos Caisson Experiment Cluster ................... 20

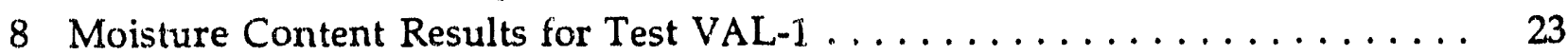

9 Moisture Content Results at hour 3.1 for Test VAL-2 . . . . . . . . . . . 27

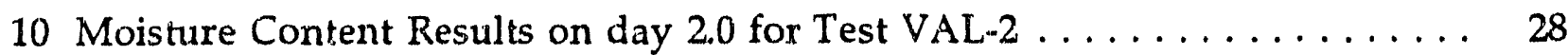

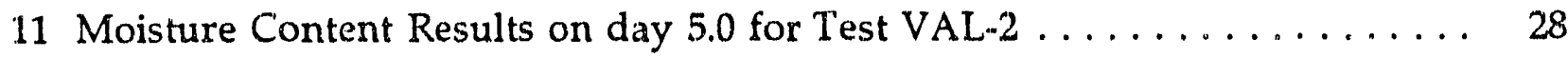

12 Moisture Content Results on day 8.0 for Test VAL-2 . . . . . . . . . . 29

13 Moisture Content Results on day 16.0 for Test VAL-2 . . . . . . . . . 29

14 Moisture Content Results on day 36.0 for Test VAL-2 ............ 30

15 Las Cruces Test Trench Experiment Area .................. 32

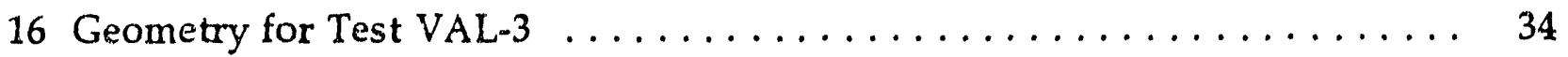

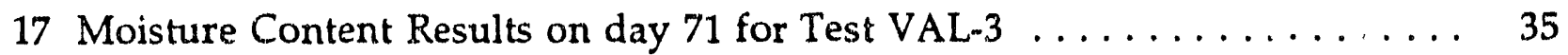

18 Moisture Content Results on day 276 for Test V.AL $-3 \ldots \ldots \ldots \ldots \ldots \ldots$

\section{List of Tables}

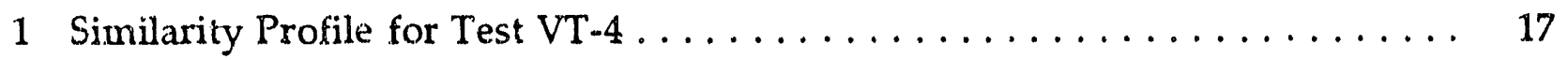

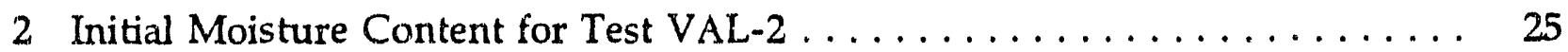

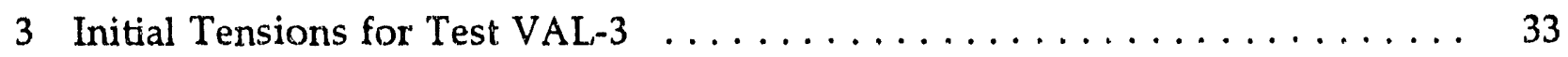

iii 


\subsection{INTRODUCTION}

The Department of Mechanical and Materials Engineering of Washington State University has conducted independent testing of the FLASH Version 3.0 computer code. The main objective of the testing focused on determining whether the code is ready for use in hydrological and environmental studies at the Idaho National Engineering Laboratory (INEL) and other Department of Energy (DOE) sites. This objective was accomplished through code verification tests (i.e., comparisons with known analytical solutions), and validation tests (i.e., comparisons with field or laboratory data). This report describes the basis, approach and results of the FLASH testing.

\subsection{BACKGROUND}

The FLASH computer code was primarily developed for use in performance assessment studies focused on evaluation of clean-up and disposal options at the INEL site. The code was specifically designed to solve both strongly and slightly nonlinear groundwater flow problems occurring at arid sites. The major processes modeled are:

o Variably saturated water flow

o Free-surface saturated water flow

o Heat transport by conduction.

Additionally, the code is capable of simulating fluid flow in fractured porous m. dia using a "dual permeability" approach.

The governing equations are solved using a Petrov-Galerkin finite element technique in conjunction with a Newton-Raphson iteration algorithm. Some of the major assumptions are: (1) fluid flow is described by Darcian or Poiseuille flow, (2) the fluid is only slightly compressible, (3) fluid flow is independent of the air phase, (4) hydraulic properties are non-hysteretic and (5) the porous media is rigid. 
The results of the verification and validation testing contained in this report provide the technical documentation certifying the operational status of the FLASH computer code version 3.0. The scope of the computational testing was limited to verification and validation testing of the FLASH code.

\subsection{COMPUTATIONAL TESTING}

The computational testing documented in this report closely follows the approach used by Magnuson et al. [1990] during the testing of the PORFLO-3 computer code.

Code verification testing was performed by comparing known analytical solutions to groundwater/porous media flow problems with the equivalent numerical solutions provided by the FLASH code. Two objectives were accomplished by the verification tests. The first was to check the accuracy and stability of the numerical solutions. The second was to demonstrate the operational fitness; i.e., determine how well the code meets design objectives. As used in this report, a computer code is defined to be fully verified when the code represents the mathematical model to a level of sufficient accuracy.

Code validation is aimed at determining how well mathematical theory used in the computer code agrees with real phenomena. The validation testing was performed by comparing numerical results with data from field experiments. The main objective was to determine a "degree of correlation" between predicted results and the observed data. As used here a computer code is said to be adequately validated when the numerical results shown reasonable correlation with the field data.

\subsection{DESCRIPTION OF TEST CASES}

Seven test problems were selected to test the FLASH code which fall into either the validation or verification category. The test cases were selected from classical groundwater texts and technical publications of field experiments conducted at various DOE sites.

The four verification tests consisted of simple boundary-value problems with known closed-form solutions. Direct comparisons of these solutions with the simulation results produced by the FLASH code were then used to quantify the accuracy of the FLASH code. 
The three validation tests were simulations of actual field experiments of increasing complexity. A qualitative judgment on the degree of correlation between the numerical results and field data was made. These validation tests were also used by different researchers to validate various other codes and thus provide an informal benchmarking of the FLASH code.

The following are brief descriptions of the four verification problems, and the three validation test.

VT-1 Philip's Solution for a Vertical Column. In this verification test, unsaturated flow in a vertical column is simulated. Fluid flow through the soil column occurs by means of capillarity and gravity. A quasi-analytic solution for this problem has been published by Philip [1957] and is embedded in the INFIL computer code (El-Kadi [1987]). This test checks the ability of the FLASH code to solve the one-dimensional form of Richard's equation.

VT-2 Aquifer Response to a Change in Reservoir Level. A simple confined aquifer is considered in this test case. Transient flow in the aquifer is induced by a sudden change of head at one end. This boundary value problem possesses a closed-form analytic solution which was derived by Carslaw and Jaeger [1959]. The purpose of this test was to verify the ability of the FLASH code can solve the one dimensional equation for confined groundwater flow.

VT-3 Regional Flow in a Groundwater Rectangle. This test case involves modeling groundwater flow in an idealized setting. The physical system is a hypothetical watershed bounded on one side by a topographic high and by and a stream on the other side. Steady-state, saturated flow is modeled for a rectangular domain. Toth [1962] presents a closed-form analytic solution for these specific conditions. This test case verifies the FLASH code can yield an accurate solution for a two-dimensional, saturated flow problem. 
VT-4 Unconfined Aquifer Draw-Down. This test considers a time-varying phreatic surface in an unconfined aquifer. The original similarity solution by Boussinesq is presented in Wilson et. al. [1979]. The solution assumes an initial water table profile which maintains its fundamental shape in time, i.e., the phreatic surface drops in response to zero head boundary conditions but maintains its fundamental shape.

VAL-1 Los Alamos Caisson Experiment for Steady-State Flow. Near saturated, steady-state flow is considered on a large length and time scale. Experimental data was taken from caisson B of the Los Alamos caisson experiment by Polzer et al. [1986]. This validation test demonstrated the ability of the FLASH code to obtain a steady-state solution to Richard's equation under field conditions.

VAL-2 Los Alamos Caisson Experiment for a Transient Water Pulse. This test was also taken from the Los Alamos caisson experiment documented by Polzer et al. [1986]. Caisson A is simulated in which a 13 centimeter water pulse is added to the caisson surface at the start of the experiment. This validation test checks the capabilities of the FLASH code to simultaneously predict water flow in both the saturated and unsaturated regimes. Additionally, the simulation tests the ability of the FLASH code to solve a flow problem in a stratified column with high pressure gradients between soil layers with vastly different hydraulic properties.

VAL-3 Two-Dimensional Unsaturated Flow: Las Cruces Trench Site. This test considers Experiment Two at the Las Cruces Trench Site where a narrow plot is irrigated over a 75.5 day period as described by Wierenga et al. [1990]. The simulation uses the in-situ soil properties of the native soil and tests the ability of the FLASH code to solve a difficult two-dimensional flow problem under dry conditions. 


\subsection{TEST APPROACH AND REQUIREMENTS}

\subsection{TEST' OBJECTIVES}

The main objective of this study was to determine the operational status of the FLASH computer code. This was accomplished by testing the major options, features and computational algorithms of the code. Three fundamental conclusions were possible: (1) the code is fully operational, (2) the code is only partially operational and some corrections and/or improvements are needed, and (3) the code is not operational and requires further development. The work presented in this report provides both quantitative and qualitative evidence to support the conclusion.

\subsection{TEST PROTOCOL}

The testing process was designed to be an independent and unbiased evaluation of FLASH, Version 3.0. To perform the testing process, a convention using the following requirements was employed:

(1) Blind testing,

(2) Independent applications, and

(3) Graduated difficulty of tests.

The first requirement was that the FLASH code be used without prior knowledge of the analytic solution. This requirement ensured the code operator could not "force" the code to agree with the analytic solution when selecting such parameters such as maximum time, integration factors, time steps or number of iterations.

The second requirement excluded the code developer from participating in the testing process. The code tester was permitted to consult the code developer only if: (1) unexplained difficulties arose, (2) code modifications were necessary to accommodate special characteristics of a specific test problem, or (3) clarification of input instructions was needed.

The final requirement allowed testing of the code over a wide range of problems and to determine the application limits of the code. 


\subsection{PERFORMANCE INDICATORS}

To evaluate the FLASH code on a consistent basis, a quantitative indicator was needed to judge the code's computational performance for each test. The relative root mean square error (RRMS) was chosen as the performance indicator for the verification tests reported here and is defined by the following formula:

$$
R R M S=\sqrt{\frac{\sum_{1=1}^{k}\left(\left(a_{1}-n_{1}\right) / a_{1}\right)^{2}}{k}} .
$$

where
$a_{i}=$ analytic solution at point $i$,
$n_{i}=$ numerical solution at point $i$, and
$k=$ number of comparison points.

Boundary nodes were excluded from the RRMS calculation where the pressure head or water content value was specified in the numerical solution.

To judge the accuracy of the verification test results, four performance categories were defined. Specific ranges of values for the RRMS were selected to define these performance categories. Performance designations and their respective ranges of RRMS values are listed below:
o Excellent
RRMS $\leq 0.01$
o Good
RRMS $\leq 0.05$
o Acceptable - RRMS $\leq 0.10$
o Unacceptable - RRMS>0.10.

Judging the quality of the validation tests was some what problematic because the validation tests are actual attempts to simulate field conditions. Field conditions represent complex physical settings which are usually simplified for incorporation into a numerical simulation. Because significant differences were expected in the results from FLASH and the experimental data gathered in the field experiments, a qualitative graphical comparison was made for such variables as pressure head and moisture content. 


\subsection{VERIFICATION TESTS}

\subsection{PHILIP'S SOLUTION FOR A VERTICAL COLUMN}

\subsubsection{VT'-1 Problem Statement}

This problem models infiltration in a vertical, homogerieous soil column. The problem is one dimensional and transient. The boundary conditions are zero pressure at the top of the soil column, which represents a saturated condition and a constant negative pressure at the bottom. The bottom pressure is the same as the uniform initial pressure in the column at the start of the simulation period. Both gravity and capillary forces create a downward flow of water in the column.

The governing equation for one-dimensional variably-saturated flow in the soil column is Richard's equation,

$$
C(\Psi) \frac{\partial \Psi}{\partial t}=\frac{\partial}{\partial z}\left[K(\Psi)\left(\frac{\partial \Psi}{\partial z}-1\right)\right]
$$

where $\Psi$ is the pressure, $K(\Psi)$ is the unsaturated hydraulic conductivity, $t$ is time, and $z$ is the vertical coordinate. $C(\Psi)$ is the specific moisture capacity and is described by,

$$
C(\Psi)=\frac{\partial \Theta}{\partial \Psi}
$$

where $\Theta$ is the volumetric water content.

\subsubsection{Test Objectives}

The objective of this test was to determine the ability of FLASH to predict the wetting front location in the soil column as a function of time.

\subsubsection{Analytic Solution}

The analytic solution was proposed by Philip [1957], which is a series solution which assumes the soil column is of infinite length. Philip's solution was 
implemented in the INFIL (El-Kadi [1987]) computer code. The solution is only quasi-analytic because the INFIL code performs a numeric integration in its computational algorithm.

\subsubsection{Input Specifications}

The soil moisture curves used to describe the functional relationship between hydraulic conductivity, moisture content, and pressure head are those proposed by Haverkamp et al. [1977] and are represented by:

$$
\theta(\Psi)=\frac{\alpha\left(\theta_{s}-\theta_{r}\right)}{\alpha+(\ln |\Psi|)^{\beta}}+\theta_{x^{\prime}}
$$

and

$$
K(\Psi)=K_{S} \frac{A}{\left(A+|\Psi|_{B}\right)}
$$

where $\Theta_{\mathrm{s}}$ is the saturated volumetric moisture content, $\Theta_{\mathrm{r}}$ is the residual moisture content, $K_{5}$ is the saturated hydraulic conductivity and $\alpha, \beta, A$ and $B$ are curve fitting parameters. The soil was Yolo light clay as used by Haverkamp et al. [1977] and the parameters were:

$$
\begin{aligned}
& \alpha=739 \\
& \beta=4.0 \\
& A=124.6 \\
& B=1.77 \\
& K_{\mathrm{s}}=1.23 \times 10^{-5} \mathrm{~cm} / \mathrm{sec} \\
& \Theta_{\mathrm{s}}=0.495 \\
& \Theta_{\mathrm{r}}=0.124 .
\end{aligned}
$$

A non-uniform grid corresponding to the solution locations output from the INFIL code was used to discretize the soil column. A total of 200 node points were used in which the node spacing increased with depth. The soil column extended to a depth of approximately $8 \mathrm{~cm}$ which was the depth of the wetting front predicted by INFIL. The grid was initially at a uniform pressure of $-601.8 \mathrm{~cm}$ which was maintained at the soil column bottom as the lower boundary condition. 


\subsubsection{Output Requirements}

The output from this verification test was the position of the wetting front after 2 hours of infiltration.

\subsubsection{Results}

The VT-1 simulation tested the ability of FLASH to solve Richard's equation for a mildly nonlinear case. Several computer runs were performed using various values of the time weighting factor in FLASH. All runs predicted movement of the wetting front to be slightly faster than the analytic solution. The position of the wetting front after 2 hours is shown in Figure 1. The RRMS values ranged from 0.09 to 0.05 for the weighting factors between 2.0 and 1.0 respectively.

The slight disagreement between the INFIL and FLASH codes may be due to the discretization of a continuous profile which is encountered in constructing any finite element or finite difference model as well as the approximations used the quasianalytic solution. The INFIL analytical solution resu'ts may cause some discrepancy because of the numerical integration. However, the errors were within an allowable range and the FLASH RRMS value was well within the "acceptable" category.

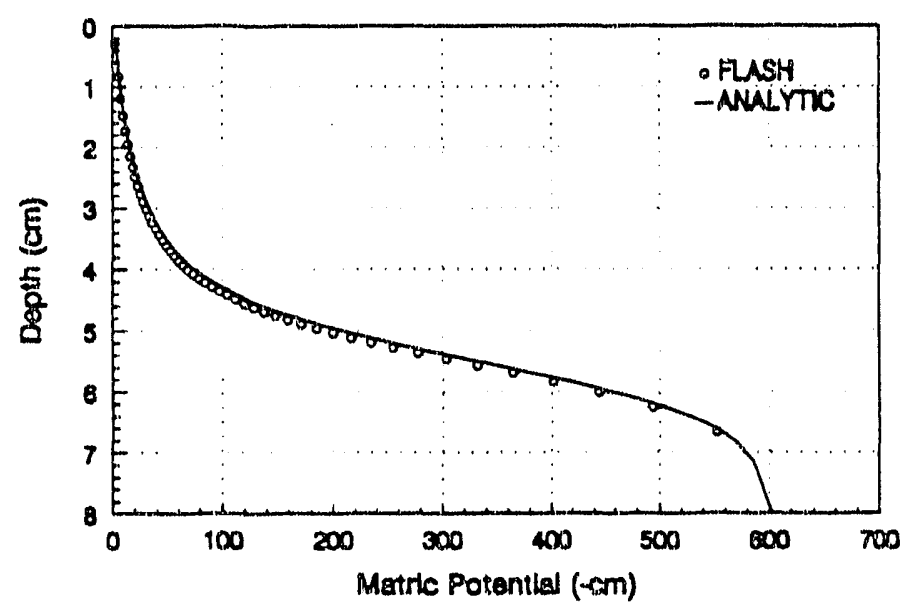

Figure 1. Comparison of Pressure Heads for Test VT-1 


\subsection{AQUIFER RESPONSE TO A CHANGE IN RESERVOIR LEVEL}

\subsubsection{Problem Statement for VT-2}

This test case considers an idealized aquifer adjacent to a reservoir as illustrated in Figure 2. Initially, the head is $16 \mathrm{~m}$ everywhere in the aquifer. At time $t=0$, the water level at one end drops to $11 \mathrm{~m}$. The governing equation for onedimensional confined groundwater flow in a homogeneous and isotropic medium is

$$
\frac{\partial^{2} h}{\partial x^{2}}=\frac{S}{T} \frac{\partial h}{\partial t}
$$

where $h$ is the inydraulic head, $x$ is the horizontal distance from the static reservoir level, $\mathrm{S}$ is the storativity, $\mathrm{T}$ is the transmissivity and $\mathrm{t}$ is time.

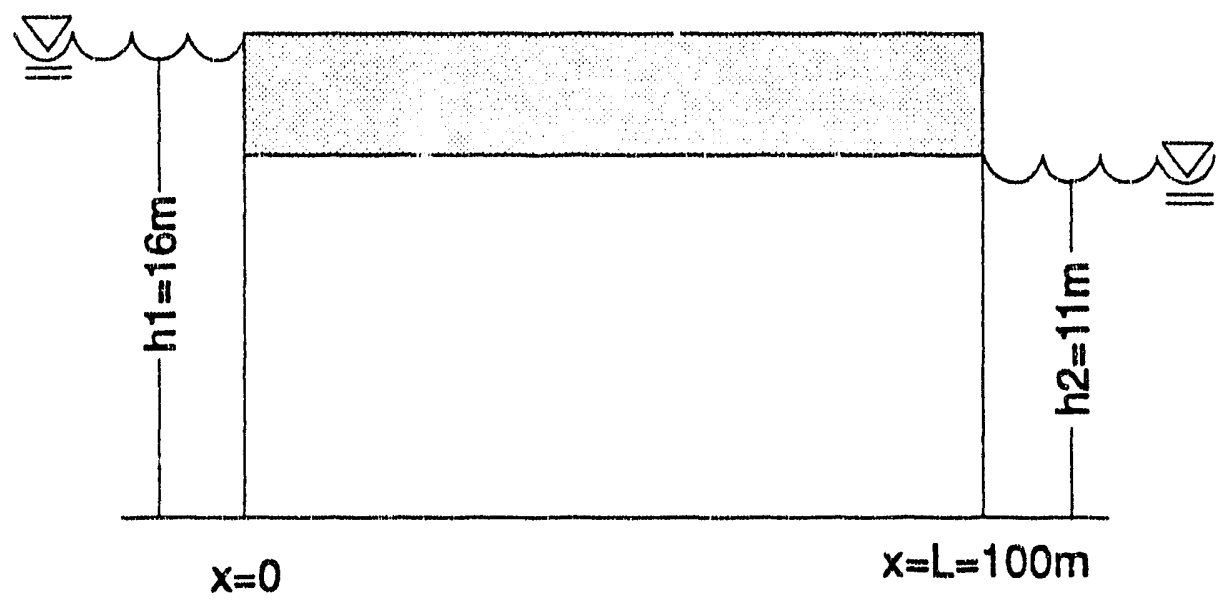

Figure 2. Simulated Aquifer for VT-2 


\subsubsection{Test Objestives}

The objective of this test was to determine how accurately FLASH could predict the transient response of the piezometric surface subject to uniform initial conditions, fixed boundary conditions, and saturated flow.

\subsubsection{Analytic Solution}

The analytic solution for this problem is an infinite power series from Carslaw and Jaeger [1959]:

$$
\begin{gathered}
h(x, t)=h_{1}+\frac{\left(h_{2}-h_{1}\right) x}{L}+ \\
\sum_{n=1,-[}\left[\frac{\left(h_{2}-h_{1}\right) \cos (n I I)}{n} \sin \frac{n \Pi x}{L} e^{-\operatorname{Tn}^{2} n^{2} t / s L^{2}}\right]
\end{gathered}
$$

where $h_{1}$ is the initial reservoir head, $h_{2}$ is the lowered reservoir head, $L$ is the length of the aquifer and all other variables are the same as those used in the governing equation.

\subsubsection{Input Specifications}

Total length of the aquifer was $100 \mathrm{~m}$ with a node spacing of $1 \mathrm{~m}$. The soil was the same Yolo light clay described in VT-1. Transmissivity was specified as 1.23 $\times 10^{-5} \mathrm{~cm}^{2} / \mathrm{sec}$ which corresponds to the saturated hydraulic conductivity for an aquifer of unit thickness and storativity was specified as 0.003 . The FLASH results were compared to the analytic solution at 11000 days. This time may seem excessively large but is necessary considering the low saturated conductivity of the soil used in the simulation.

\subsubsection{Output Requirements}

The head profile verses horizontal distance was compared to the analytic solution after 11000 days of drainage. 


\subsubsection{Verification Test Results}

Verification test VT-2 tested FLASH's ability to solve the one-dimensional heat equation. Again, several computer runs were made varying the time weighting factor between 1.0 and 2.0. For each run the agreement between the FLASH results and the analytic solution was excellent. The RRMS values varied between 0.0008 and 0.0002 with the best results obtained by using a weighting factor of 2.0. Graphical agreement was also excellent as shown in Figure 3 where the FLASH and analytical solutions appear identical.

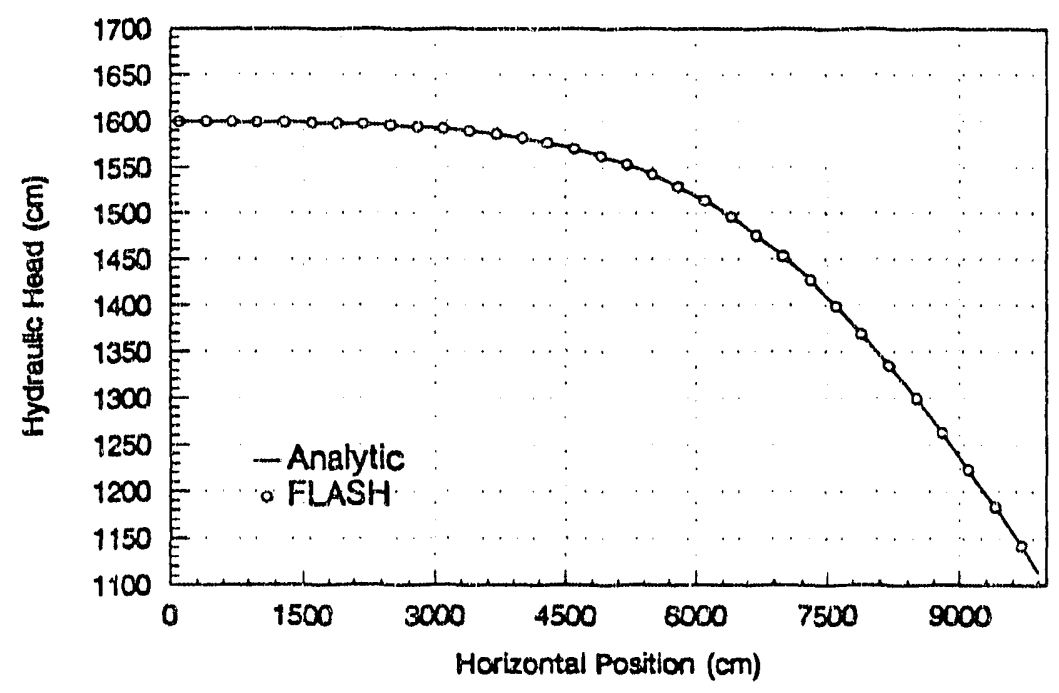

Figure 3. Comparison of Pressure Heads for Test VT-2 


\subsection{REGIONAL FLOW IN A GROUNDWATER RECTANGLE}

\subsubsection{Problem Statement for VT-3}

This test case simulates an idealized watershed bounded on one side by a topographic high representing a regional ground water divide and on the other side by a major stream which represents another regional groundwater divide. Furthermore, the aquifer is assumed to be underlain by impermeable rock. The governing equation is

$$
\frac{\partial^{2} h}{\partial x^{2}}+\frac{\partial^{2} h}{\partial y^{2}}=0
$$

which is Laplace's equation. A linearly increasing head was used for the top boundary condition and no flow boundary conditions were used on the sides and bottom. In this equation, $h$ represents hydraulic head and $x$ and $y$ represent horizontal and vertical distances respectively.

\subsubsection{Test Objectives}

The objective of this test was to determine how accurately FLASH solves the governing equation for a saturated two-dimensional steady-state flow problem.

\subsubsection{Analytic Solution}

A classic closed form solution of this problem was presented by Toth [1962] assuming a homogeneous and isotropic aquifer, a linear water table configuration, and a rectangular domain. The solution is

$$
h(x, y)=y_{0}+\frac{c s}{2}-\frac{4 c s}{\Pi^{2}} \Sigma_{m=0},-\frac{\cos [(2 m+1) \Pi x / s] \cosh [(2 m+1) \Pi y / s]}{(2 m+1)^{2} \cosh \left[(2 m+1) \amalg y_{0} / s\right]}
$$

where $y_{0}$ is the vertical height of the aquifer, $s$ is the horizontal length of the aquifer, $c$ is the slope of the constant head boundary condition, and $x$ and $y$ are coordinate locations. 


\subsubsection{Input Specifications}

An aquifer $10000 \mathrm{~cm}$ in height and $20000 \mathrm{~cm}$ long was modeled. The slope of the constant head upper boundary condition was 0.01 . The remaining boundaries were treated as no-flow boundaries. The analytical solution is independent of hydrological parameters. The aquifer domain was discretized using a $100 \mathrm{~cm}$ node spacing in both the $x$ and $y$ directions and the FLASH code was run in a steady state mode.

\subsubsection{Output Requirements}

The steady state head profile throughout the aquifer was compared to the Toth solution both graphically and in terms of the RRMS values.

\subsubsection{Verification Test Results}

The simulation results compared extremely well with the analytic solution. The graphical comparison showed no visible differences between the FLASH solution and the solution by Toth [1962]. These results are illustrated in Figure 4. The RRMS comparison supported this close agreement with a value of $4.1 \times 10^{-5}$. This value is well within the "excellent" range and is probably near the precision limit of the computer used in the simulation. From these results, it has been shown FLASH does a excellent job of solving the equations for saturated flow in two dimensions. 


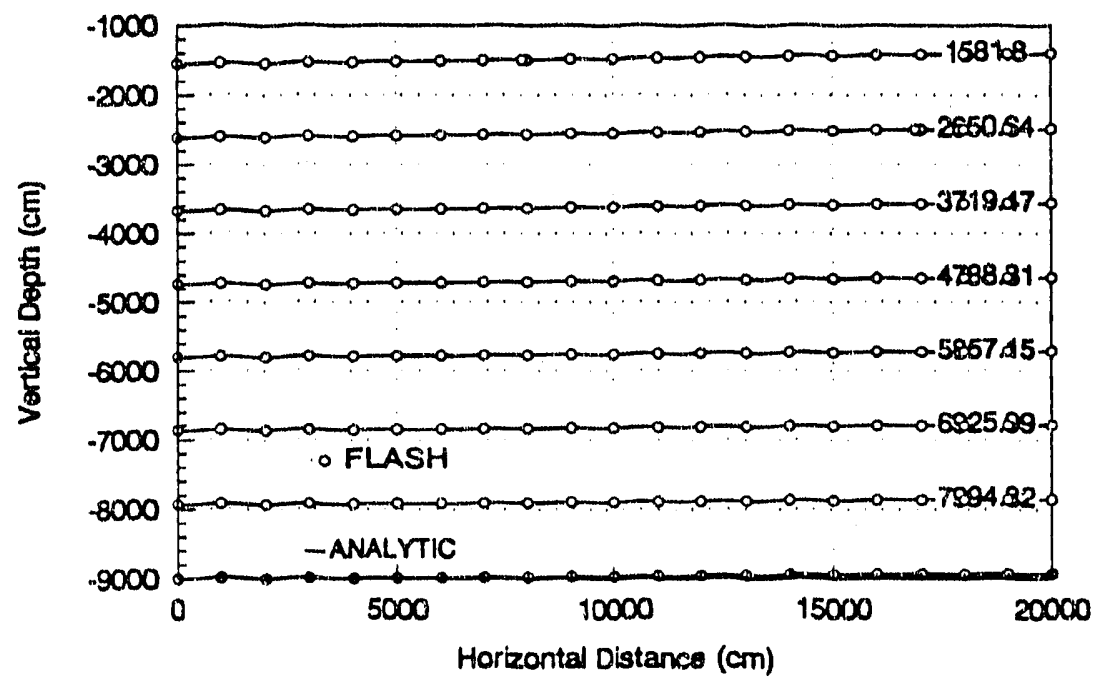

Figure 4. Comparison of Pressure Heads for Test VT-3 


\subsection{BOUSSINESQ SIMILARITY SOLUTION FOR AN UNCONFINED AQUIFER}

\subsubsection{Problem Statement for VT-1}

This test simulates an unconfined aquifer, i.e, the depth of the aquifer may change with time. Additionally, this test case uses the Dupuit assumption which assumes the slope of the phreatic surface is very small and all groundwater flow is essentially horizontal.

The governing equation for this problem is the Boussinesq equation, given by

$$
S_{y} \frac{\partial h}{\partial t}=\frac{\partial}{\partial x}\left(T_{x x} \partial \frac{h}{\partial x}\right)
$$

where $h$ is pressure head, $t$ is time, $S_{y}$ is specific yield, $x$ is horizontal position, and $T_{x x}$ is transmissivity.

\subsubsection{Test Objectives}

The objective of this test was to determine the ability of the FLASH code to predict unconfined aquifer draw-down subject to the Dupuit assumption.

\subsubsection{Analytic Solution}

The analytic solution is a similarity solution and is taken from Wilson et al. [1979]. The solution assumes an initial water table profile that maintains its fundamental shape over time, i.e., the phreatic surface drops through time but maintains the same fundamental shape. The solution is given by:

$$
h / h_{0}=\frac{x(x / I)}{4.46209\left(\frac{K h_{0} t}{S_{y} L^{2}}\right)+1}
$$

where $h$ is pressure head, $h_{o}$ is initial pressure head, $S_{y}$ is specific yield, $L$ is aquifer length and $X(x / L)$ is the similarity profile and is presented in Table 1 below. 
Table 1. Similarity Profile for Test VT-4

$\mathrm{x} / \mathrm{L} \quad \mathrm{x}$

$\begin{array}{ll}0.00 & 0.000 \\ 0.05 & 0.412 \\ 0.10 & 0.575 \\ 0.15 & 0.692 \\ 0.20 & 0.782 \\ 0.25 & 0.853 \\ 0.30 & 0.968 \\ 0.35 & 0.949 \\ 0.40 & 0.978 \\ 0.45 & 0.994 \\ 0.50 & 1.000\end{array}$

\subsubsection{Input Specifications}

A $20000 \mathrm{~m}$ long aquifer was discretized using 201 uniformly spaced nodes. The saturated conductivity and specific yield were specified as $10000 \mathrm{~m} /$ day and 0.1 , respectively. Boundary conditions were designated as zero pressure while the initial conditions corresponded to the similarity profile multiplied by the initial pressure head of $100 \mathrm{~m}$.

\subsubsection{Output Requirements}

The output for this test was the non-dimensional pressure head profile at $2.988,8.964$ and 26.89 days along with the variation of pressure head in time at the aquifer center. 


\subsubsection{Verification Test Results}

The RRMS comparison for the simulation showed excellent results. The RRMS values were $0.00209,0.00147$, and 0.00168 for days $2.988,8.964$, and 26.89 respectively. Graphical comparison between the simulation results and the analytical solution for the days listed above are illustrated in Figure 5. Additionally, a graphical comparison of the falling head with time occurring at the aquifer center is shown in Figure 6. These RRMS values are well within the "excellent" category and the graphical results show an almost perfect match between the analytical and numerical solutions. Overall, the results of this verification test show the FLASH code successfully solves the equation for saturated unconfined flow.

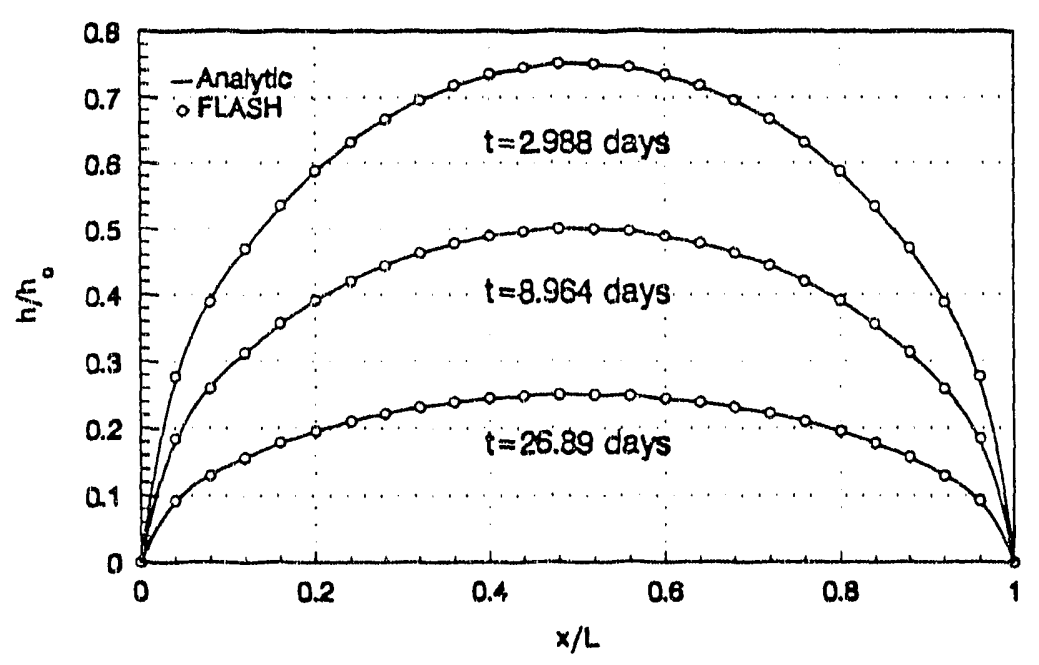

Figure 5. Comparison of Relative Pressures for Test VT-4 


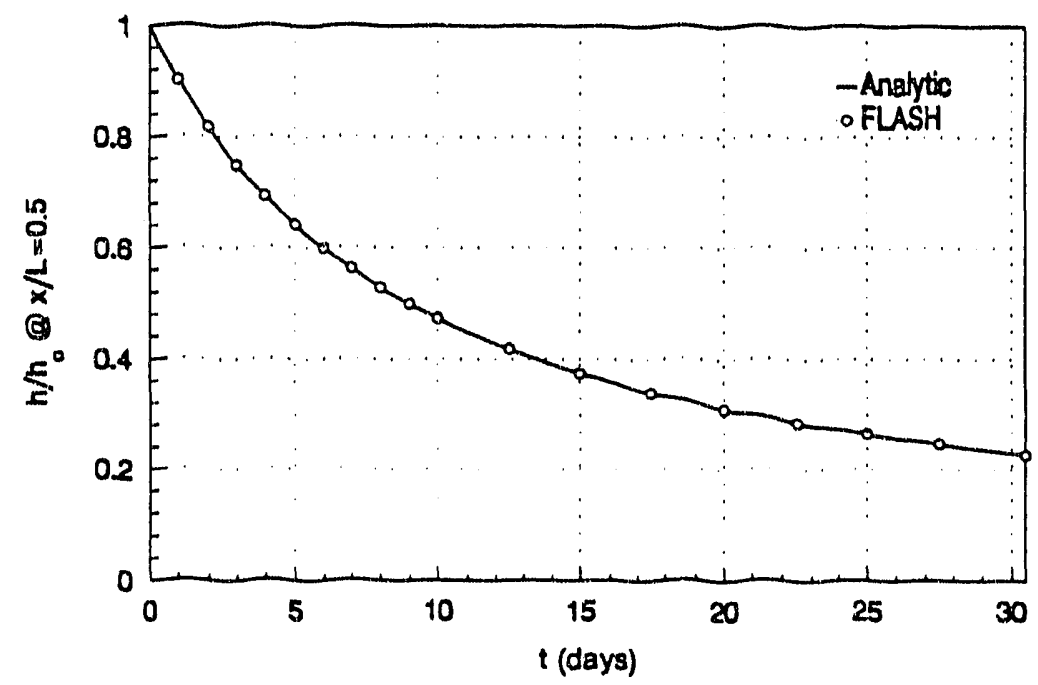

Figure 6. Comparison of Head Variation for Test VT-4 


\subsection{VALIDATION TESTS}

\subsection{LOS ALAMOS CAISSON EXPERIMENT FOR STEADY-STATE FLOW}

\subsubsection{VAL-1 Problem Statement}

This validation test considers $1-D$ steady-state unsaturated flow in caisson $B$ of the Los Alamos caisson experiment. The simulation tests the capability of FLASH to predict unsaturated flow conditions in a soil column under conditions of steady-state flow. The test is similar to a simulation conducted by Perkins et al. [1985] in the validation of the TRACR3D code (Travis [1984]).

\subsubsection{Experimental Background}

The experiment was conducted in the one of the six caissons in the experiment ciuster at the Engineered Test Facility located at Los Alamos National Laboratory. The caisson is 3 meters in diameter by 6 meters deep as illustrated in Figure 7.
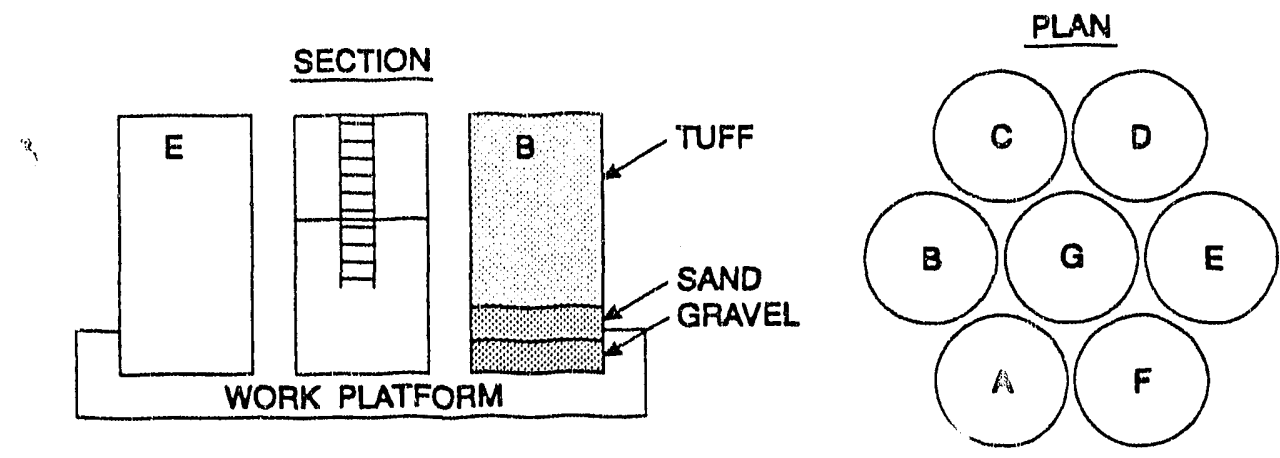

Figure 7. Los Alamos Caisson Experiment Cluster 
Caisson $B$ was used for the steady state experiment and was filled with the native Los Alamos tuff. The tuff was excavated using front end loaders and then crushed by running the front end loaders over the tuff before being screened through a 12.7 millimeter screen. The tuff was then mixed in a cement truck with enough water to obtain a moisture content of 10 to $13 \%$ ensuring maximum mixture density. Finally, the tuff was compacted into the caisson in 15 to $20 \mathrm{~cm}$ layers using "jumping jacks". The caisson was then instrumented with horizontal and vertical neutron probe access tubes along with solute samplers and thermocouple psychrometers.

Water was then applied at a rate of $200 \mathrm{ml} / \mathrm{min}$ until a steady-state condition was achieved, i.e. flow into the top equals flow out the bottom. At this time water content and degree of saturation as function of depth was determined.

\subsubsection{Input Specifications}

The tuff hydraulic properties were taken from Abeele [1984] and the soil moisture curve can be represented as

$$
\theta_{V}=1.1455-\frac{\ln T}{4.8678} .
$$

Where $\Theta_{V}$ is moisture content and $\Psi$ is matric potential in $\mathrm{KPa}$. The moisture curve is valid for moisture content ranging from 0.35 to 0.90 of saturation. This soil moisture curve was then input into a curve fitting program to calculate the Van Genuchten parameters and the relative hydraulic conductivity curve needed in FLASH. The parameters obtained were

$$
\begin{aligned}
& \alpha=0.001251 / \mathrm{cm} \\
& N=4.81312 \\
& K_{\mathrm{s}}=0.000146 \mathrm{~cm} / \mathrm{sec} \\
& \Theta_{\mathrm{s}}=0.346 \\
& \Theta_{\mathrm{g}}=0.12 .
\end{aligned}
$$


A uniform grid of 50 elements and 101 nodes was used to discretize the 550 $\mathrm{cm}$ deep soil profile. A constant flux of $4.7157 \times 10^{-5} \mathrm{~cm}$ was specified as the surface boundary condition which corresponded to the $200 \mathrm{ml} / \mathrm{min}$ applied to the caisson surface. The free drainage bottom boundary condition in FLASH was tried but failed to work, therefore a fixed head was assigned as the bottom boundary condition. The head was determined by trying several different head values until a uniform pressure was obtained throughout the soil column indicating a steady state condition.

\subsubsection{Output Requirements}

The output from this validation test was the degree of saturation as a function of depth.

\subsubsection{Validation Test Results}

Figure 8 contains the FLASH results and the experimental values and shows the FLASH code does a good of predicting unsaturated steady-state flow conditions. The results are within the experimental error and appear to be a good "linear curve fit" of all the experimental data points. The experimental data also suggests there are non-uniformities in the soil profile which were not considered in the FLASH simulation. In conclusion, the FLASH code did an excellent job of predicting moisture content under conditions of steady state flow. 


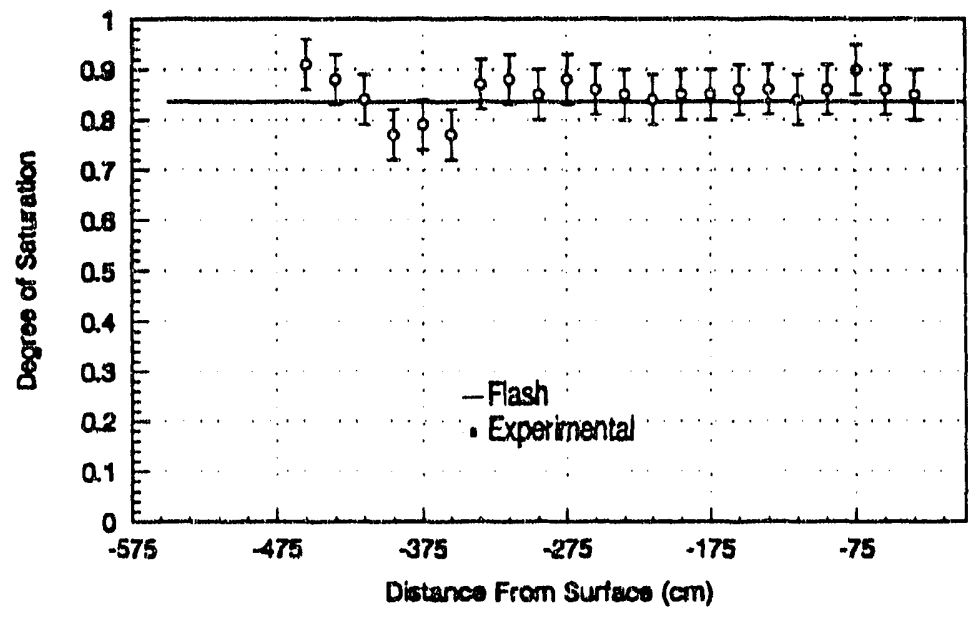

Figure 8. Moisture Content Results for Test VAL-1 


\subsection{LOS ALAMOS CAISSON EXPERIMENT FOR A TRANSIENT WATER PULSE}

\subsubsection{Val-2 Problem Statement}

This validation test simulates the water pulse experiment in caisson $A$ of the Los Alamos caisson experiment. The ability of the FLASH code to model transient saturated/unsaturated flow in one dimension on a large length and time scale is tested. This test was also patterned after the validation tests conducted by Perkins et al. [1985] to validate the TRACR3D code (Travis [1984]).

\subsubsection{Experimental Background}

Caisson A was similar to caisson B described in VAL-1, but instead of steady state flow, a water pulse experiment was conducted. The caisson was prepared for the experiment by maintaining $4 \mathrm{~cm}$ of ponded water on the soil surface until moisture measurements indicated the soil in the caisson was as near saturation as possible. The caisson was then allowed to drain and moisture content measurements were made to provide initial conditions for the simulation.

Water was then added until a ponded depth of 4 inches was obtained. After 4 hours and 45 minutes, the water had completely ssaked into the soil and the top of the caisson was sealed to prevent further infiltration by rainfall or water loss from evaporation. The rate of water drainage out of the caisson bottom along with water content and soil water tension were measured at various depths over a period of 6 weeks.

\subsubsection{Input Specifications}

The tuff hydraulic properties were the same as those used in VAL-1 but in addition, the sand and gravel located at the caisson bottom were included in the simulation. The actual hydraulic properties of the sand and gravel used in the caisson construction were unknown. Therefore, values for $\Theta_{R}, \Theta_{S}$ and $K_{s}$ were assumed and soil moisture curves for the sand and gravel were taken from Intera [1989]. The hydraulic properties were then input into a curve fitting program to determine the van Genutchen parameters and relative hydraulic conductivity curves. The parameters for sand were 


$$
\begin{aligned}
& \alpha=0.015341 / \mathrm{cm} \\
& N=2.8812 \\
& K_{S}=0.005 \mathrm{~cm} / \mathrm{sec} \\
& \Theta_{R}=0.02 \\
& \Theta_{S}=0.35
\end{aligned}
$$

and the parameters for gravel were

$$
\begin{aligned}
& \alpha=0.181841 / \mathrm{cm} \\
& N=21.6842 \\
& K_{S}=0.03 \mathrm{~cm} / \mathrm{sec} \\
& \Theta_{R}=0.02 \\
& \Theta_{S}=0.40 .
\end{aligned}
$$

The initial conditions were interpolated from the moisture contents measured just prior to the experiment. The initial moisture content of the sand was assumed to be near saturation while the moisture content of the gravel was assumed to be near the residual saturation. Observed initial conditions were taken from Perkins et al. [1985] and are listed in Table 2.

Table 2. Initial Moisture Content for Test VAL-2

Depth (cm) Volumetric Moisture (\%)

$0-80$ 17.9

80-152

18.6

$152-228$

18.2

228-308

19.4

308-388

20.8

388-468

22.2

$468-550$

26.0

$550-575$

32.7

$575-600$

2.2 
Nodal spacings of $5 \mathrm{~cm}$ were used to a depth of $520 \mathrm{~cm}$ where the spacing was reduced to $0.5 \mathrm{~cm}$ down to the column bottom at $600 \mathrm{~cm}$. The tenfold reduction in nodal spacing was necessary because of high matric potential gradients at the tuffsand and sand-gravel interfaces.

Two runs were made with FLASH to simulate the water pulse experiment. The first run extended to 4.75 hours i.e. (the time in which water was still soaking into the tuff) and a constant flux of $0.00076 \mathrm{~cm} / \mathrm{sec}$ was specified as the top boundary condition corresponding to a total application of 4 inches over the observed period of ponding. The second run used initial conditions generated from the first run and continued to 36 days. During this run, the top boundary condition was changed to a zero flux and both runs used a specified head of zero as the bottom boundary condition.

\subsubsection{Output requirements}

Degree of saturation as a function of depth was compared graphically to the experimental data taken from Perkins et al. [1985] at 6 time periods. The time periods were 3.1 hours, 2.0 days, 5.0 days, 8.0 days, 16 days, and 1.2 months.

\subsubsection{Validation Test Results}

Graphs of experimental data superimposed over the FLASH results are provided in figures 9 through 14 for the soil region of the profile and show the FLASH code predicted saturated flow very near the surface during the infiltration period which quickly becomes unsaturated a few centimeters below the surface. The FLASH code also predicted the water pulse would reach the profile bottom after 36 days while experimental data indicate changes in soil moisture are very slight below $400 \mathrm{~cm}$.

A comparison between the code predictions and the experimental data is excellent at 3.1 hours as indicated in figure 9. At days 2.0, 5.0, and 8.0 their still appears to be good agreement with the experimental data as the FLASH results are within the margin of experimental error for most data points. Days 16 and 36 show the water pulse moving beyond 400 meters but they still agree with the experimental data at locations above 400 meters. 
The FLASH results show the initial conditions are damping out faster than the experimental data suggesting the estimates of hydraulic conductivity may have been slightly larger than the true value. Overall the FLASH code did a good job of solving a multilayered problem which had very high pressure gradients existing in the soil profile.

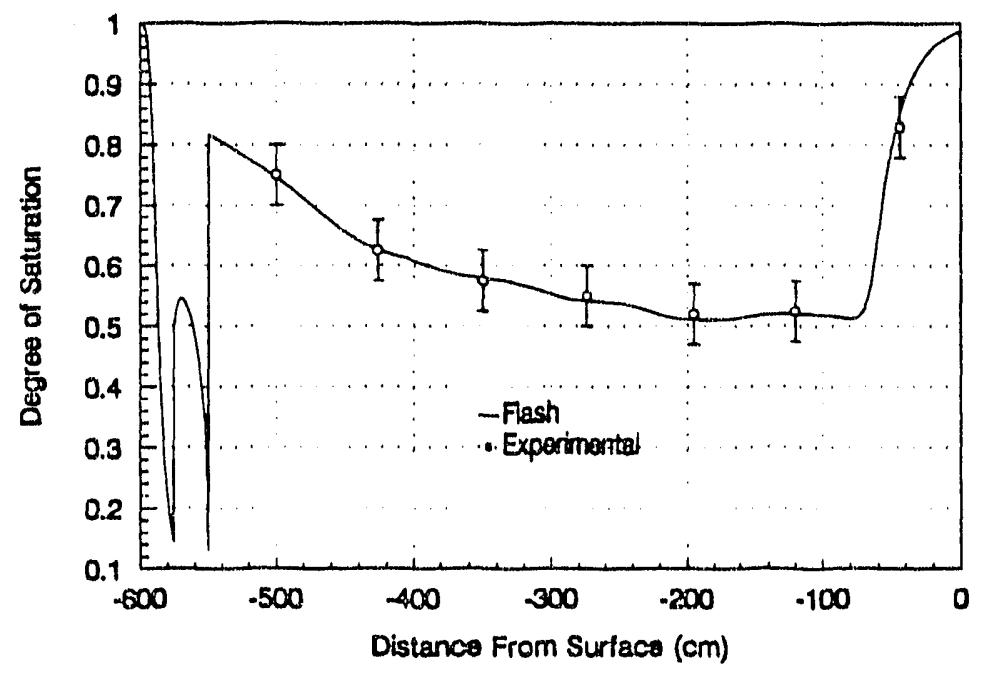

Figure 9. Moisture Content Results at hour 3.1 for Test VAL-2 


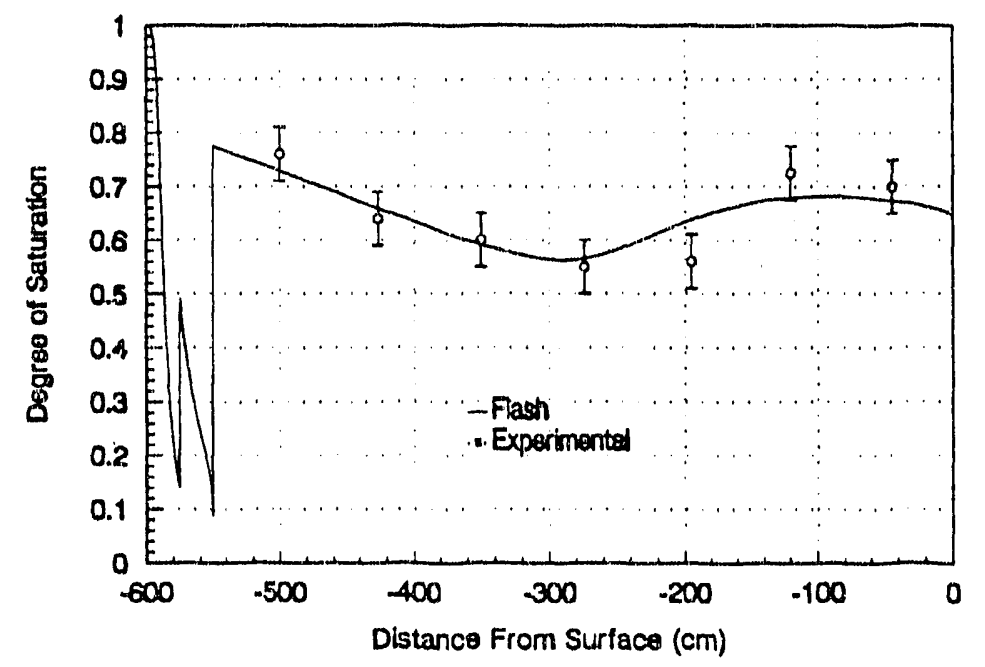

Figure 10. Moisture Content Results on day 2.0 for Test VAL-2

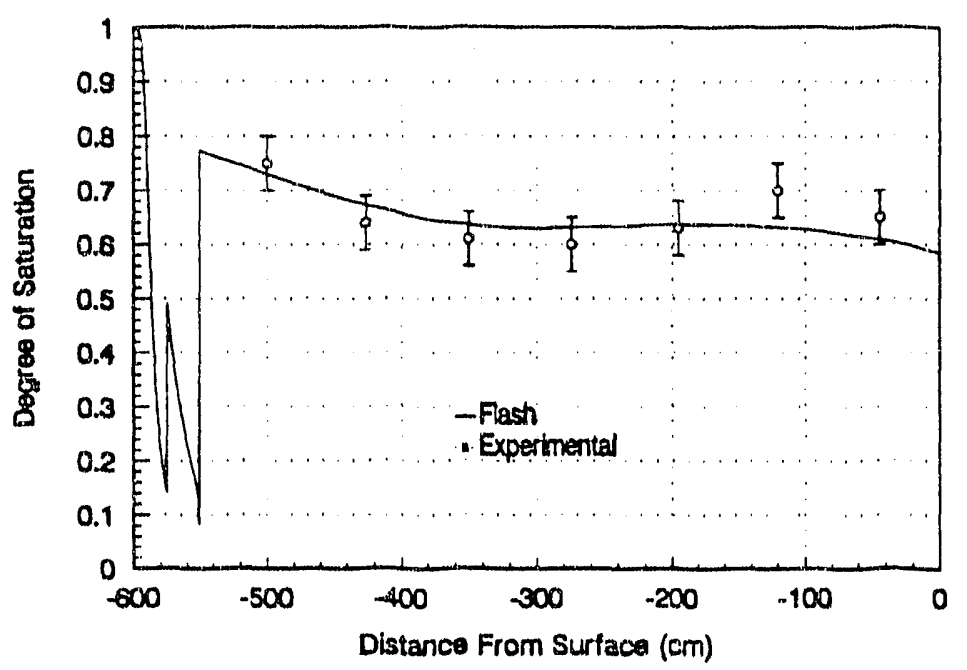

Figure 11. Moisture Content Results on day 5.0 for Test VAL-2 


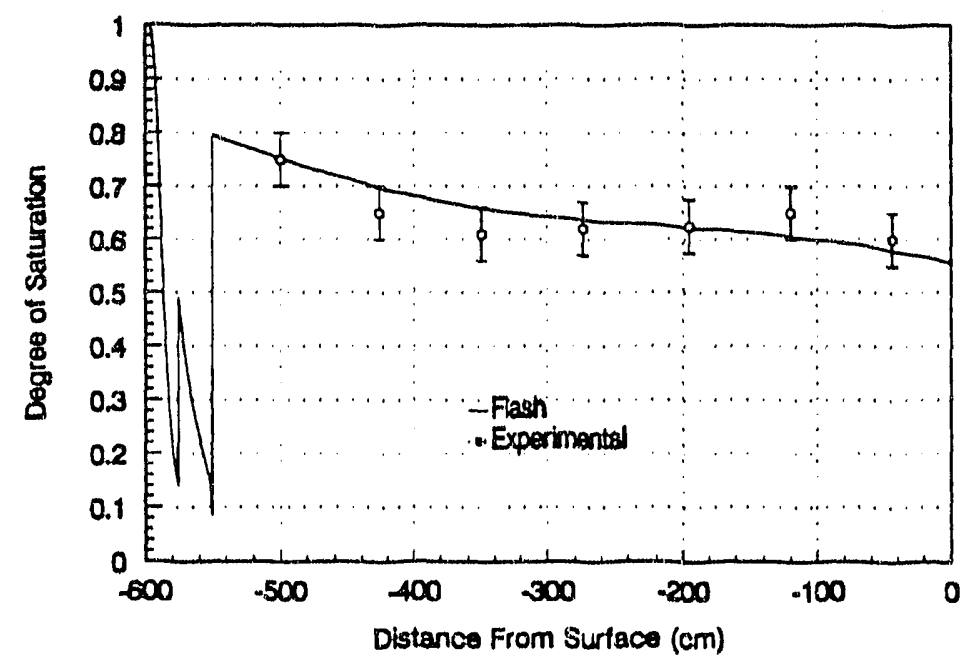

Figure 12. Moisture Content Results on day 8.0 for Test VAL-2

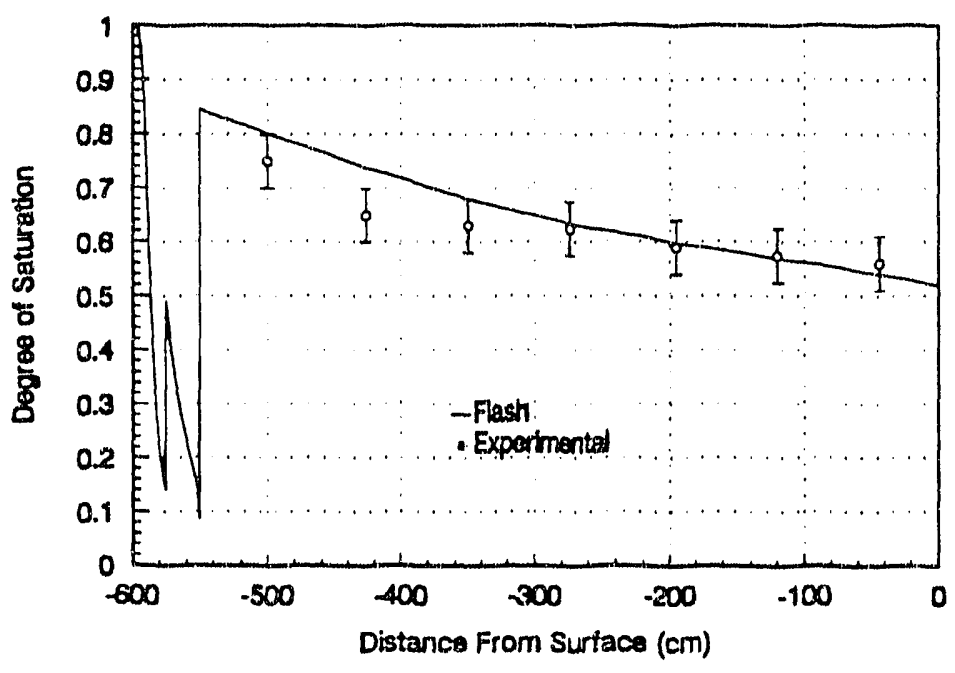

Figure 13. Moisture Content Results on day 16.0 for Test VAL-2 


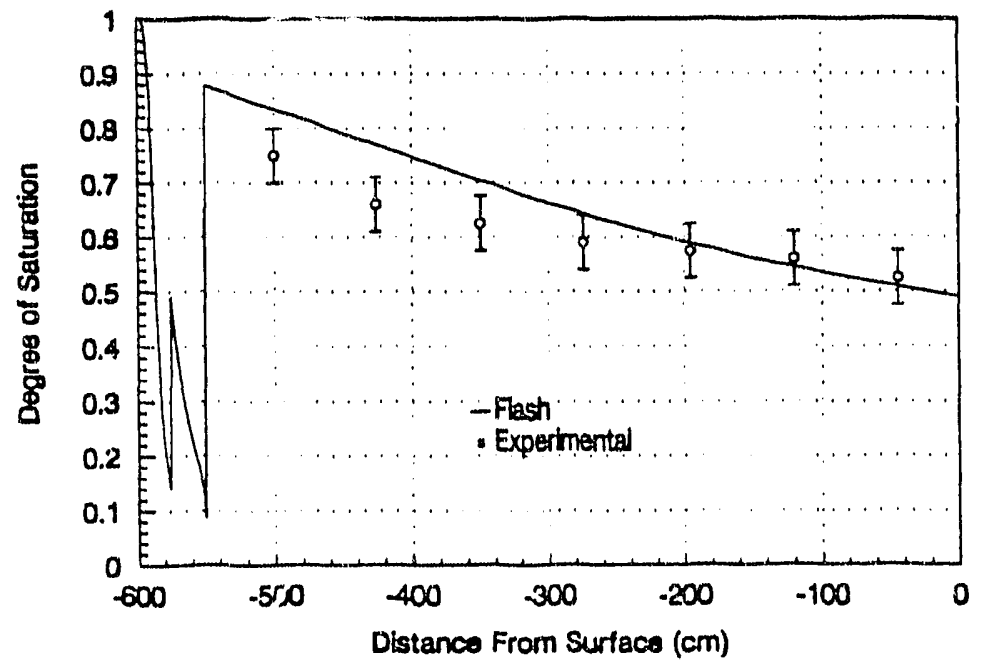

Figure 14. Moisture Content Results on day 36.0 for Test VAL-2 


\subsection{LAS CRUCES TRENCH EXPERIMENT}

\subsubsection{Problem Statement for VAL-3}

This validation test, taken from Wierenga et al. [1990], considers an infiltration experiment conducted at the Las Cruces Trench Site in which a narrow plot is irrigated over a 75.5 day period. A cross-section perpendicular to the irrigated strip is simulated. This simulation tests the ability of the FLASH code to simulate a transient two-dimensional unsaturated flow problem.

\subsubsection{Experimental Background}

A deep trench was constructed at the Las Cruces Trench Site providing horizontal access to adjacent irrigated plots for tensiometer and solution samplers. Additionally, neutron access tubes were installed vertically near the trench extending from the surface to a depth of $6 \mathrm{~m}$. A schematic of the test trench is provided in Figure 15.

Water was applied to a $1.2 \mathrm{~m}$ by $12 \mathrm{~m}$ area adjacent to the test trench through a series of closely spaced drip enitters. The water was applied at a rate of 0.43 $\mathrm{cm} /$ day over a 75.5 day period and neutron probe readings were taken every 4 to 5 days. 


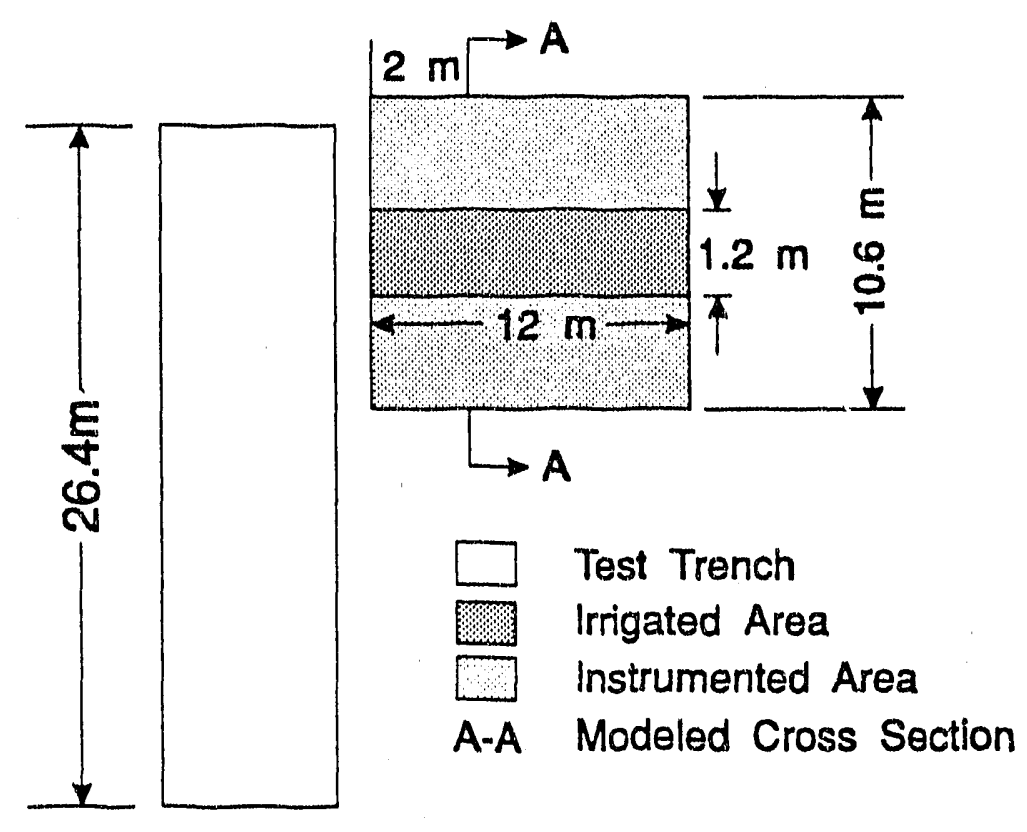

Figure 15. Las Cruces Test Trench Experiment Area

\subsubsection{Input Specifications}

A modeling approach similar to Wierenga et al. [1990] was used in this validation test. A uniform soil (homogeneous soil without layering) was used in the simulation and the hydraulic parameters were taken from Wierenga et al. [1990]. The van Genutchen parameters were

$$
\begin{aligned}
& \alpha=0.055011 / \mathrm{cm} \\
& N=1.5093 \\
& K_{\mathrm{s}}=0.003126 \mathrm{~cm} / \mathrm{sec} \\
& \Theta_{\mathrm{R}}=0.0828 \\
& \Theta_{\mathrm{S}}=0.3209 .
\end{aligned}
$$

Initial conditions were taken from initial tension readings before the start of the experiment and are shown in Table 3. Linear interpolation was then used to estimate initial tensions at intermediate depths. 
Table 3. Initial Tensions for Test VAL-3.

Depth $(\mathrm{cm}) \quad$ Head $\left(\mathrm{cm} \mathrm{H}_{2} \mathrm{O}\right)$

25

143.9

75

170.2

100

249.3

150

215.5

210

28860

285

36980

360

47090

435

48020

510

53300

585

56330

660

64940

Symmetry was utilized and only one half of the experimental domain was modeled. A region $600 \mathrm{~cm}$ deep by $508.33 \mathrm{~cm}$ wide was discretized using a uniform 30 by 25 element grid in the vertical and horizontal directions, respectively. All boundary conditions were specified as no flux except for the upper left hand corner where a surface flux of $0.43 \mathrm{~cm} /$ day was applied during the first 75.5 days. The computational grid is illustrated in Figure 16. 


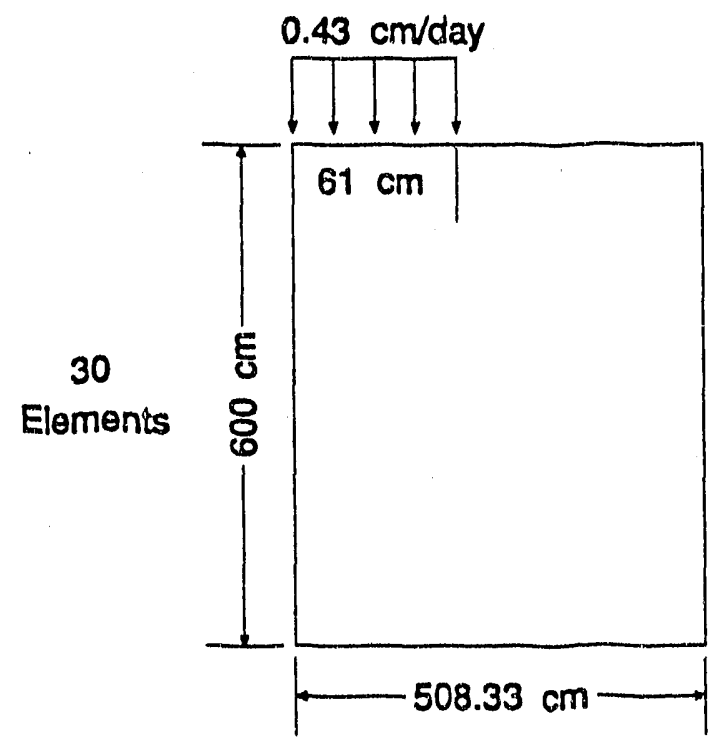

25

Elements

Figure 16. Geometry for Test VAL-3

\subsubsection{Output Requirements}

Volumetric saturations throughout the modeled cross-section at 71 and 276 days were compared graphically with the experimental data taken from nevtron probes located $2 \mathrm{~m}$ from the trench wall.

\subsubsection{Validation Test Results}

The experimental data and the FLASH simulation are shown with the numerical sesults in Figures 17 and 18. Plots of the experimental data show a large amount of spatial variability present in the observed water contents indicating significant soil layering probably exists in the test trench soil. Although the effects of heterogeneity in the soil have distorted the redistribution of water in the experimental data, there appears to be relatively good qualitative agreement between the FLASH results and the experimental data. General regions of the experimental data tend to have the same overall moisture content as predicted by FLASH. 
The FLASH code did a relatively good job of predicting moisture contents in a two dimensional problem considering the complexity of the soil located at the La Cruces Test Trench. Additionally, the FLASH code results agreed very closely with the modeling results obtained by Wierenga et al. [1990].

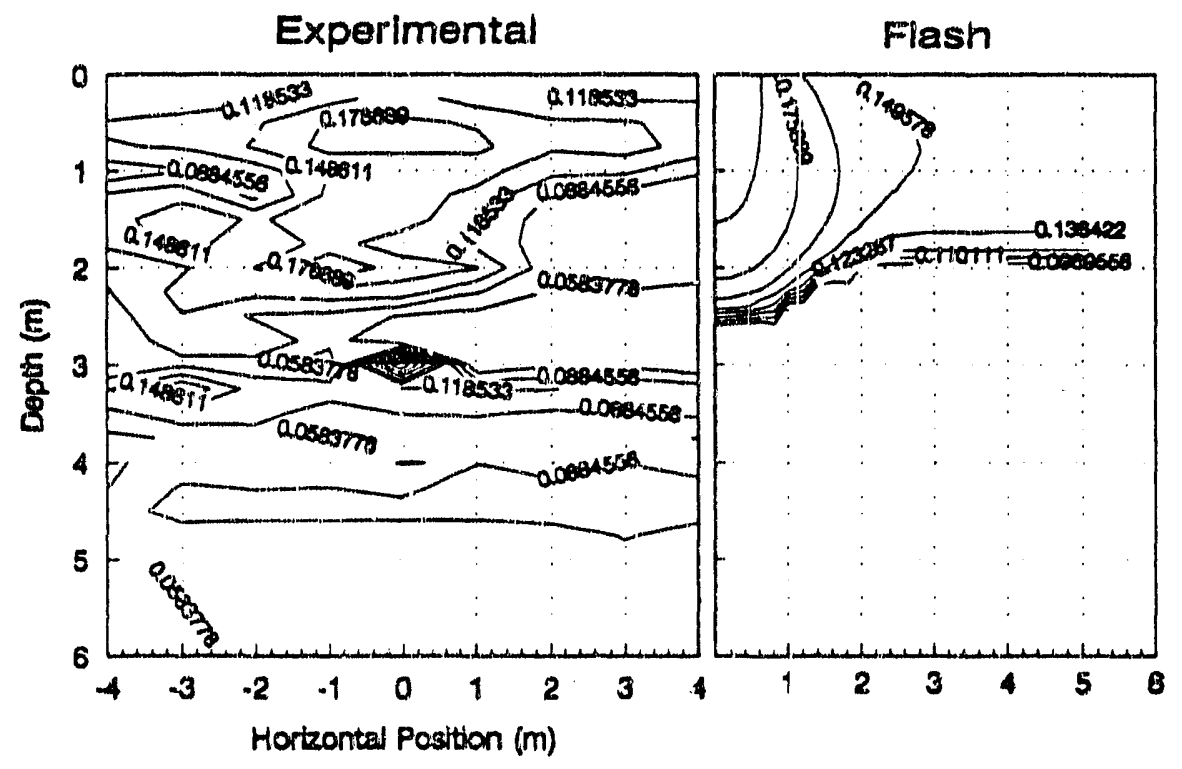

Figure 17. Moisture Content Results on day 71 for Test VAL-3 


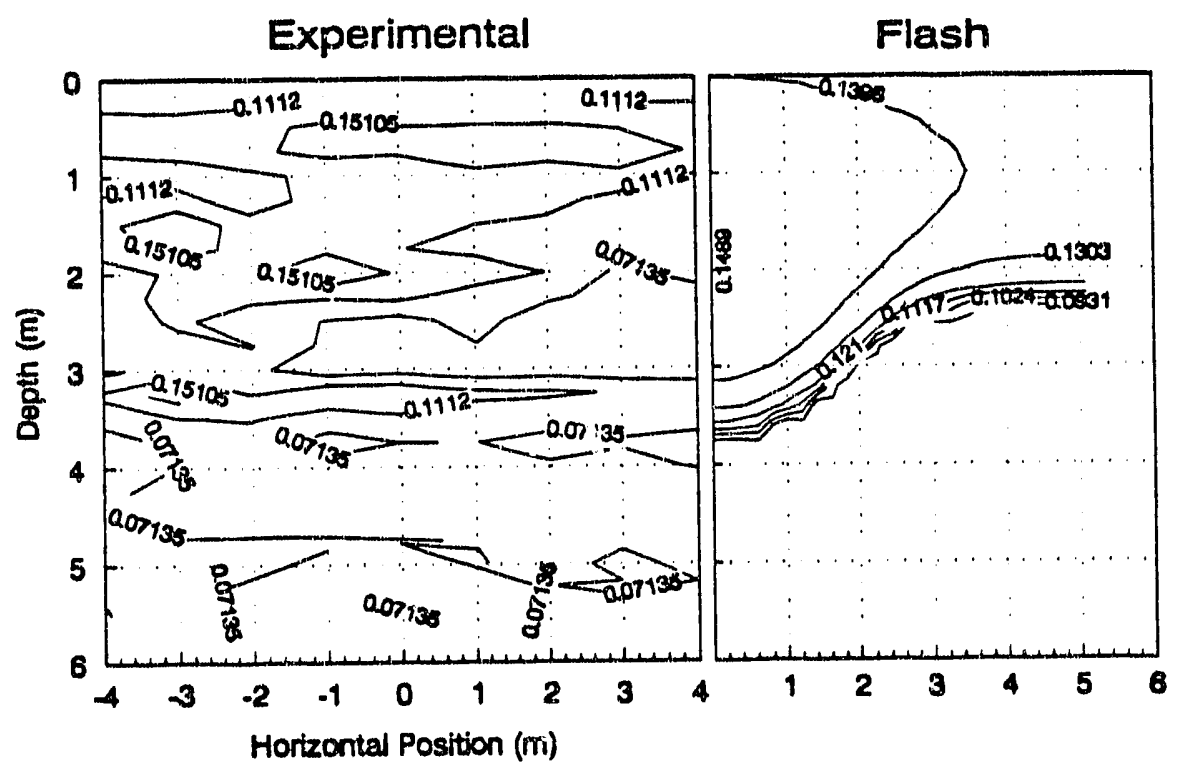

Figure 17. Moisture Content Results on day 276 for Test VAL-3 


\subsection{FINDINGS AND RECOMMENDATIONS}

Detailed computational testing of the FLASH computer code was performed with two main objectives in mind: (1) to determine the operational status of version 3.0 of the code and (2) to examine the general capabilities and limitations of the code. These objectives were accomplished through code verification (i.e., comparison with known solutions) and validation (comparison with experimental data). These verification and validation tests were specifically designed to

o Check the correctness of the FORTRAN coding

- Assess computational accuracy

o Test the code's capability to simulate diverse hydrologic conditions.

\subsection{GENERAL FINDINGS}

The results of the four verification test cases were judged in terms of graphical comparisons and relative root mean square (RRMS) error values. Three of the four verifications tests showed no visible difference between the analytical solution and the numerical solution in the graphical comparisons and the RRMS values approached the limits of machine precision. The results of the vertical column flow problem indicated only "acceptable" performance, however the quasi-analytic solution for this verification test was suspect. Nonetheless, the overall results indicated the FLASH code did an excellent job of the fundamental equations for groundwater flow.

Results of the three validation tests showed good qualitative agreement between the FLASH results and the experimental data. Specifically, most of the data from the 1-dimensional tests were well within the experimental measurement error. The 2-dimensional validation test showed good agreement in magnitude but poor agreement in shape of the moisture content profile over the modeled cross-section. This was probably due to differences between the uniform soil assumption in the FLASH model and the heterogeneity occurring the test trench soil itself. Overall, the validations tests showed the FLASH code can simulate complex "real" hydrologic conditions. 
Based on the results of this testing it is concluded that FLASH version 3.0 is a versatile and powerful two-dimensional analysis tool for isothermal fluid flow patterns in both the saturated and unsaturated regimes and is ready for use in hydrological and environmental studies at the INEL and other DOE sites. Furthermore, the code appears to be fully operational except for the unit gradient boundary condition. The unit gradient boundary condition assumes the change in pressure head over change in distance is unity and allows unrestricted flow equal to the hydraulic conductivity of the soil. The unit gradient is often used in groundwater models, especially for extremely deep vadose zone simulations.

\subsection{RECOMMENDED REFINEMENTS}

The FLASH computer code is a powerful analysis tool which incorporates the many of the best "state of the art" features available in the groundwater modeling and represents a high level of code refinement. However, the independent code testing reported here has identified two specific areas where the code could benefit from further refinement. These are, (1) computational changes and (2) input and output options. Specific recommendations for improvements in these areas are discussed below.

\subsubsection{Computational Changes}

Results of the validation tests demonstrated that the computational algorithms are highly efficient and well programmed. The automatic time step algorithm which either halves or doubles the time step in accordance with solution parameters such as maximum relative change in pressure head and number of iterations worked well and was well liked by the tester. However, occasionally the algorithm would increase the time step beyond the convergence limits and the maximum relative error specified by the user would be exceeded. Slightly adjusting the reference point for doubling the time step would probably resolve the problem.

Another improvement would be to allow the use of sources and sinks within a modeled profile (currently only surface flux boundary conditions are allowed). The internal sources and sinks would allow modeling of underground irrigation, leakage from buried tanks, and water removal by wells. 
Finally, the tester could not get the FLASH code to recognize the unit gradient (free drainage) lower boundary condition as mentioned in section 5.1 above. This last recommended change is the only critical item in need of refinement and should be corrected before the code is released.

\subsubsection{Input and Output Options}

The narrative style command sequence used in the input file for the FLASH code was user friendly and appeared to work well. This narrative style input used special keywords to control the simulation as well as describe the input of model parameters. The input scheme also allowed comment lines to be inserted in any location to document such items as data sources, units and assumptions. However, the comment card proceeding the soil properties table requires the keyword Material to appear in the comment card. If a comment card convention is followed where only documentation appears in comment lines, the keyword should be specified elsewhere in the input file, not in a comment line.

The output file provided a good history of the simulation run, however the output did not allow easy plotting of solution parameters such as pressure head, moisture content, and fluid velocity vs. position. An option should be incorporated to output solution parameters in a two column format (depth vs. head etc.) for 1dimensional simulations and a three column format ( $x$ position and $y$ position, vs. head etc.) for 2-dimensional simulations.

\subsection{RECOMMENDATIONS FOR ADDITIONAL TESTING}

The verification and validation test cases were aimed at testing the major feature of the FLASH code, namely uncoupled fluid flow. However, other features of the code would benefit from further testing. These are:

o heat transfer,

o coupled heat transport and fluid flow,

o flow in discrete fractures (dual permeability model),

Additionally, formal benchmark testing should be performed to provide a performance comparison with similar codes. 


\section{ACKNOWLEDGMENTS}

The authors with to thank a number of individuals who provided assistance with this project. First and foremost, the authors thank Swen O. Magnuson, of EG\&G Idaho, Inc., for his assistance in trouble-shooting the test cases and for his thorough review of the draft report. The authors also wish to thank Robert G. Baca, from Southwest Research Inc., for providing assistance with FLASH code and answering the author's numerous questions. Finally, the authors wish to thank A. Jeff Sondrup, EG\&G Idaho, Inc., for his careful review of the draft report and Tony $R$. Moser, EG\&G Idaho, Inc., for his assistance with the report graphics. The quality of the report was greatly improved by their contributions. 


\section{REFERENCES}

1. Abeele, W.V., Hydraulic Testing of Bandelier Tuff, LA-10037-MS, Los Alamos National Laboratory, Los Alamos, NM (1984).

2. Baca, R.G. and S.O. Magnuson, Independent Verification and Benchmark Testing of the UNSAT-H Computer Code, Version 2.0, EGG-BEG-8811, EG\&G Idaho, Inc., Idaho Falls, ID (1990).

3. Bear, J. and A. Verruijt, Modeling Groundwater Flow and Pollution, D. Reidel, Dordrecht, Holland (1987).

4. Carslaw, H.S., J.C. Jaeger, Conduction of Heat in Solids (2nd ed.), Oxford University Press, London (1959).

5. El-Kadi, A.I., INFI, International Groundwater Modeling Center, Holcomb Research Institute, IN (1987).

6. Hills, R.G. and P.J. Wierenga, Model Validation at the Las Cruces Trench Site, NUREG/CR-5716, Department of Soil and Water Science, University of Arizona, Tucson, AZ (1991).

7. Hills, R.G., P.J. Wierenga and D.B. Hudson, "The Second Las Cruces Trench Experiment: Results and Two-Dimensional Flow Predictions", Water Resources Research, 47, 2707-2718 (1991).

8. Haverkamp, R., M. Vanclin, J. Touma, P.J. Wierenga, and G. Vachaud, "A Comparison of Numerical Simulation Models for One-Dimensional Infiltration", Soil Sci. Soc. Am. J., 41, 285-294 (1977).

9. INTERA Technologies, Inc., Comparison of Unsaturated Flow and Transport Models with Volume and Nitrate Measurements from a Pilot-Scale, In-Situ Lysimeter With Different Geometry Low Level Radioactive Waste Designs, Austin, TX (1989).

10. Magnuson, S.O., R.G. Baca and A.J. Sondrup, Independent Verification and Benchmark Testing of the PORFLO-3 Computer Code, Version 1.0, EGG-BG9175, EG\&G Inc., Idaho Falls, ID (1990).

11. Perkins, B., B. Travis and G. DePoorter, Validation of the TRACR3D Code for Soil Water Flow Under Saturated/Unsaturated Conditions in Three Experiments, LA-10263-MS, Los Alamos National Laboratory, Los Alamos, NM (1985). 
12. Philip, J.R., "Numerical Solution of Equations of the Diffusion Type with Diffusivity Concentrated-Dependent II", Australian Journal of Physics, 10(2), 2942 (1957).

13. Polzer, W.L., H.R. Fuentes, E.P. Springer and J.W. Nyhan, Modeling Study of Solute Transport in the Unsaturated Zone, LA-10730-MS, Los Alamos National Laboratory, Los Alamos, NM (1986).

14. Toth, J., "A Theory of Groundwater Motion in Small Drainage Basins in Central Alberta, Canada", Journal of Geophysical Research, Vol 67, 4375-4387 (1962).

15. Travis, B.J., TRACR3D: A Model of Flow and Transport in Porous-Fractured Media, LA-9667-MS, Los Alamos National Laboratory, Los Alamos, NM (1984).

16. Wang, H.F. and M.P. Anderson, Introduction to Groundwater Modeling; Finite Difference and Finite Element Methods, W.H. Freeman and Company, San Francisco, CA (1982).

17. Wierenga, P.J., A.F. Toorman, D.B. Hudson, J. Vinson, M. Nash and R.G. Hills, Soil Physical Properties at the Las Cruces Trench Site, NUREG/CR-5441, Department of Soil and Water Science, University of Arizona, Tucson, AZ (1989),

18. Wierenga, P.J., D.B. Hudson, R.G. Hills, I. Porro, M.R. Kirkland and J. Vinson, Flow and Transport at the Las Cruces Trench Site, Experiments 1 and 2, NUREG/CR-5607, Department of Soil and Water Science, University of Arizona, Tucson, AZ (1990).

19. Wilson, J.L., L.R. Townley and Antonio Sa da Costa, Mathematical Development and Verification of a Finite Element Aquifer Flow Model, Aquifem-1, Report 248, Massachusetts Institute of Technology, Cambridge, MA (1979). 


\section{APPENDIX A - SUMMARY OF RRMS RESULTS}

The relative root mean square (RRMS) was computed in the verification tests and used to judge the quality of the FLASH simulation results. This appendix contains a summary of the FLASH RRMS values, their corresponding classification (see section 2.3), and a short description of the comparison made.

Problem

RRMS

Classification

Description

VT-1

VT-2

VT-3

VT-4
$5.0 \times 10-2 \quad$ Acceptable

$2.0 \times 10-4 \quad$ Excellent

$4.1 \times 10-5 \quad$ Excellent

$2.1 \times 10-3 \quad$ Excellent

$1.5 \times 10-3 \quad$ Excellent

$1.7 \times 10-3 \quad$ Excellent
Matric Potential at 2 hours

Total Head at 11,000 days

Total Head at Steady-State

Relative Head at 2.988 days

Relative Head at 8.964 days

Relative Head at 26.89 days 

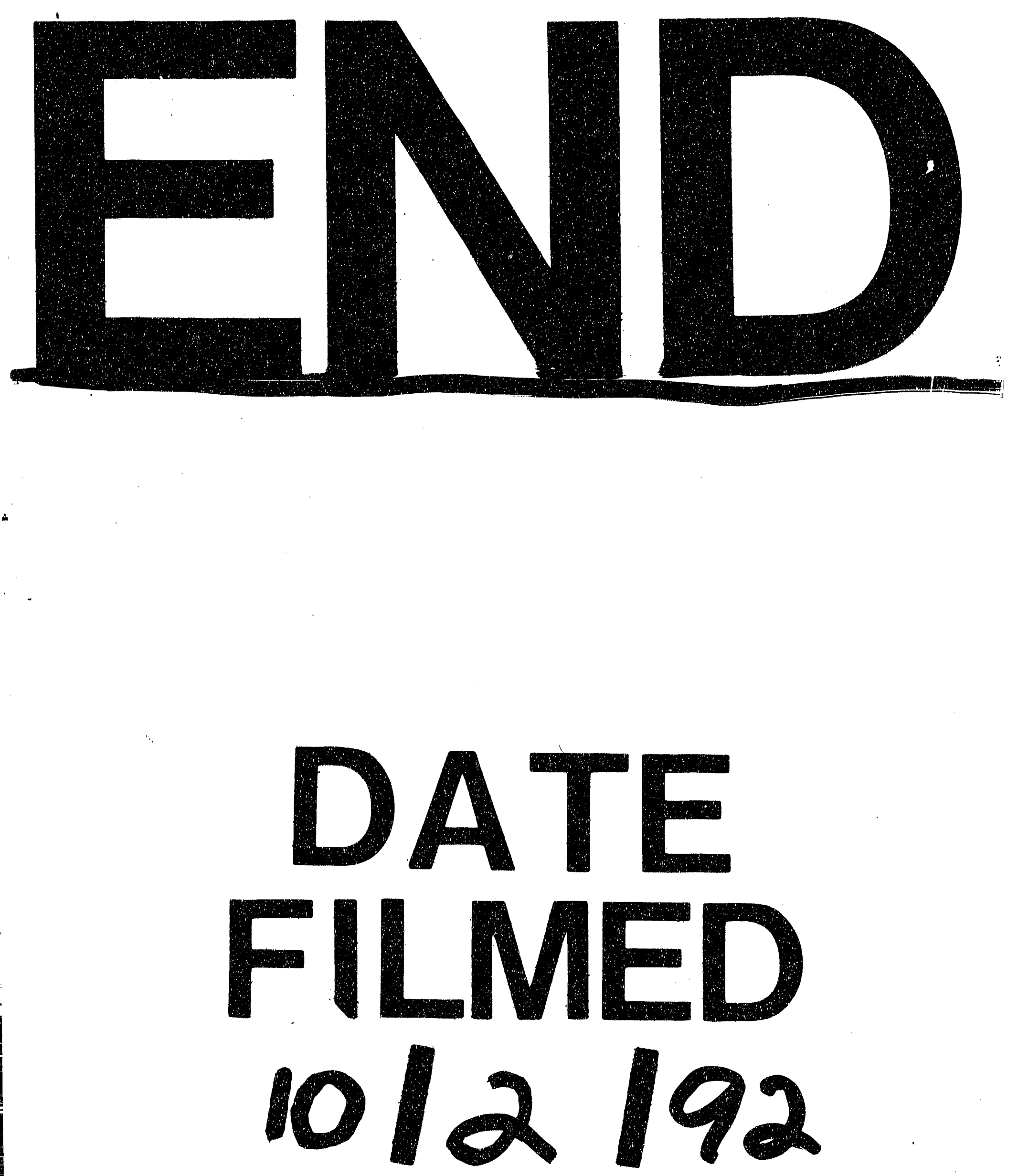
n+1 m!n

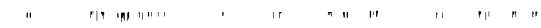

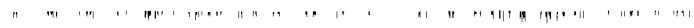

